\title{
Syntheses and Photochemical Reactions of Bis-Thymine Derivatives
}

\author{
Minoo Jalili Moghaddam, Kyoko Kanbara, Shigeo Hozumi, \\ Yoshiaki INAKI, and Kiichi TAKEMOTO \\ Department of Applied Fine Chemistry, Faculty of Engineering, \\ Osaka University, Suita, Osaka 565, Japan
}

(Received December 8, 1989)

\begin{abstract}
Bis-thymine derivatives were synthesized and their photochemical reactions in solution and in the film state upon irradiation of UV light above $270 \mathrm{~nm}$ were studied. The irradiation of these compounds caused the intramolecular and/or intermolecular photodimerization of thymine bases, leading to the photocyclization or photopolymerization of them. The probability of these reactions depended on the conformation of the thymine bases in the ground state, length and rigidity of the linking compound, and the reaction conditions in solution or in the film state.
\end{abstract}

KEY WORDS Bis-Thymine Derivatives / Isomers / Photodimerization / Intermolecular / Intramolecular / UV Irradiation / Photopolymerization /

The photodimerization of pyrimidine bases upon irradiation of UV light is well known due to the photochemical transformation of nucleic acids and their lethal effects on biological systems. The photochemical reactions of thymine bases lead to four isomeric cyclobutanetype photodimers (Figure 1), ${ }^{1,2}$ depending on the reaction state and conformation of the monomeric parents. The photodimerization reaction, however, is a photoreversible reaction and the photodimers revert to their parents upon UV irradiation at shorter wavelengths. ${ }^{3,4}$ It is known that the quantum efficiency for photodimerization of thymine bases in solution is low, whereas that in an aggregated solution or dry film is high. ${ }^{5}$

Studies on photodimerization of oligo- and polynucleotides have illustrated that the conformation of thymine bases has important roles on the photodimerization efficiency, as well as the mechanism of formation. Photodimerization proceeds with high efficiency through a singlet precursor when the bases are stacked, and takes place with lower efficiency through a triplet precursor when they are not.
In this regard, we made a series of detailed studies on the polymers containing pyrimidine bases, as well as, dimer and oligomer models. $^{7-12}$ It was shown that in dilute solutions of dimeric compounds, photodimerization occurred only intramolecularly, and proceeded through a triplet precursor. Although in a solid matrix, stacked conformation could be formed and photodimerization proceeded through a singlet as well as a triplet precursor. We prepared bis-thymine derivatives with different sterical conformations and spacings between the thymine units (Figure 2), and studied the structural effects on the photochemical reactions of these compounds. The photochemical reactions of these compounds were studied both in solution and in the film state and were compared with those of the polymeric compounds. From photochemical reactions in the film state, the applicability of the bis-thymine derivatives to deep-UV photoresist are discussed. 
<smiles>Cc1cn(C)c(=O)[nH]c1=O</smiles><smiles>CN1C(=O)NC(=O)[C@@]2(C)[C@H]1[C@@H]1N(C)C(=O)NC(=O)[C@@]12C</smiles>

cis-syn

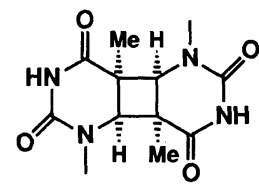

cis-anti

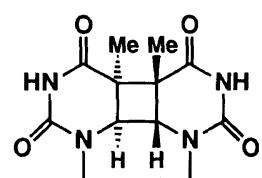

trans-syn

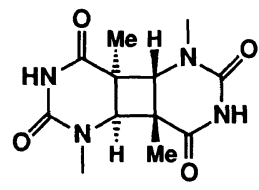

trans-anti

Figure 1. Isomers of the thymine photodimer.<smiles>Cc1cn(CCCC(=O)CCCC(=O)OCCn2cc(C)c(=O)[nH]c2=O)c(=O)[nH]c1=O</smiles><smiles>CCn1cc(C)c(=O)[nH]c1=O</smiles><smiles>CCn1c(=O)c(C)cn(C)c1=O</smiles>

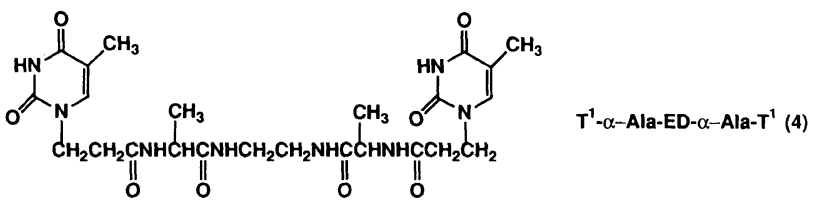<smiles>[2H]n1c(=O)n(CCCn2cc(C)c(=O)[nH]c2=O)n(C(=O)CCn2cc(C)c(=O)[nH]c2=O)c1=O</smiles> 


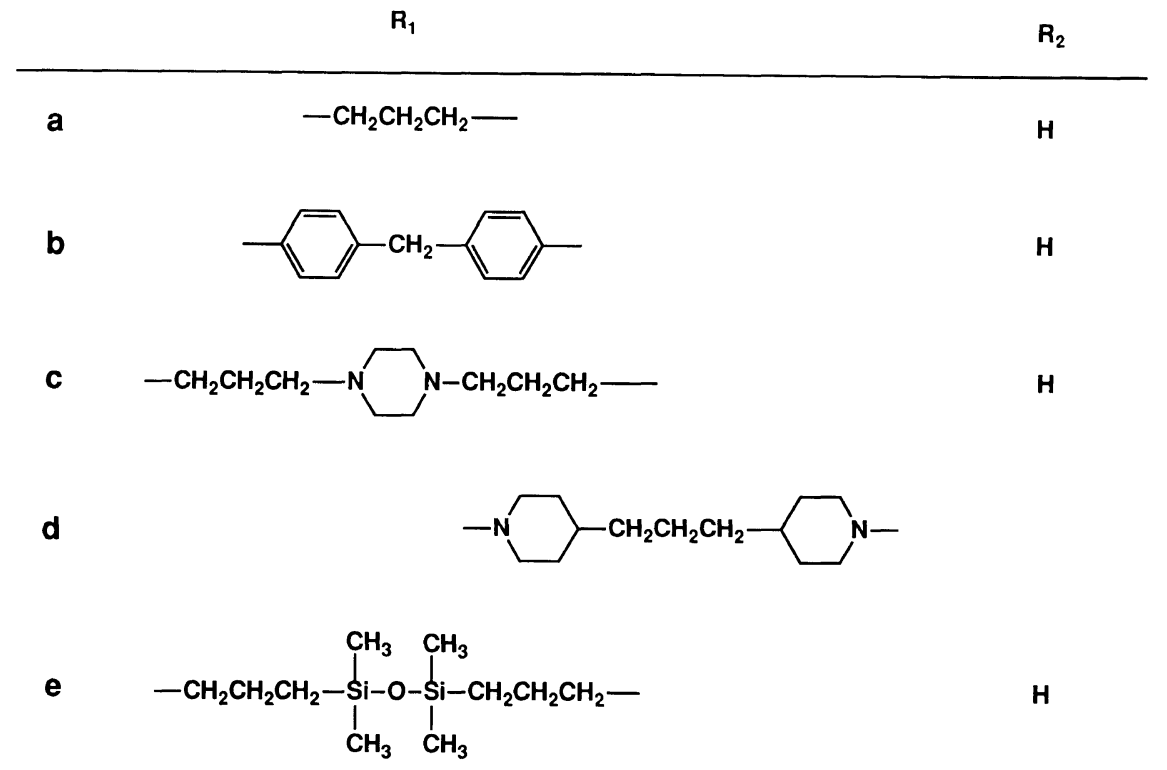

Figure 2. Synthetic bis-thymine compounds.

\section{EXPERIMENTAL}

\section{Materials}

Monomer Syntheses

1-(2-Hydroxyethyl)thymine (6)

1-Methyll-3-(2-hydroxyethyl)thymine (8)

These compounds were prepared by the same method as described in our earlier report. ${ }^{12}$

1-(2-Carboxyethyl)thymine (9)

Thymine was reacted with ethyl acrylate followed by hydrolysis according to the method reported by Overberger and Inaki, ${ }^{13}$ to give 1-(2-carboxyethyl)thymine in high yield.

\section{Dimeric Model Syntheses}

Bis[2-(thymin-1-yl)ethyl] glutarate $\left(\mathrm{T}^{1}-\mathrm{T}^{1}\right)$ (1)

This dimeric model was prepared by the method reported in the literature. ${ }^{8}$

1-(2-Glutaroylhydroxyethyl)thymine (7)

A mixture of hydroxyethyl thymine (6) $(0.85 \mathrm{~g}, 0.005 \mathrm{~mol})$ and glutaric anhydride $(0.80 \mathrm{~g}, 0.0075 \mathrm{~mol})$ was heated to the melting point of the reactant, and the reaction was carried out with heating while stirring the reactant mixture. Compound 7 was obtained by adding and decantation of excess diethyl ether in $95 \%$ yield $(1.35 \mathrm{~g})$. IR $\left(\mathrm{KBr}, \mathrm{cm}^{-1}\right)$ : 3160, 3050, 2830, 1730, 1690, 1460, 1420, 1380, $1370,1350,1310,1250,1160,1080,1060,1010$, $920,870,780,760$, and 690 .

2-(Thymin-1-yl)ethyl 2-(1-methyl-thymin-3yl)ethyl glutarate $\left(\mathrm{T}^{1}-\mathrm{T}^{3}\right)(2)$

The obtained compound (7) $(1.3 \mathrm{~g}, 0.0045$ mol) was dissolved in pyridine $(5 \mathrm{ml})$ and dicyclohexylcarbodiimide (DCC) (1.2 g) was added to it. The reaction mixture was cooled and 1-methyl-3-hydroxyethylthymine (8) $(0.83 \mathrm{~g}, 0.0045 \mathrm{~mol})$ was added and the reaction mixture was stirred for $5 \mathrm{~h}$ at room temperature. The solvent was then removed under reduced pressure and chloroform was added to the residue several times to remove the insoluble dicyclohexylurea (DCU). This process was repeated with acetone. After removal of DCU and evaporation of the solvent, the remaining DCC was removed from the system by extraction in water-chloroform for several times. Chloroform was then evaporated under reduced pressure and product 2 was obtained by precipitation and decantation in diethyl ether for several times. Yield; 59\% (1.21 g); mp 
$144-145^{\circ} \mathrm{C} . \mathrm{IR}\left(\mathrm{KBr}, \mathrm{cm}^{-1}\right): 3200,3070,2970$, $1730,1690,1660,1450,1370,1350,1280,1250$, $1160,1070,1020,910,830$, and $760 .{ }^{1} \mathrm{H}$ NMR (dimethyl sulfoxide- $d_{6}$ (DMSO), $25^{\circ} \mathrm{C}, 60$ $\mathrm{MHz}$, ppm): $1.8 \quad\left({ }^{5} \mathrm{C}-\mathrm{CH}_{3}\right), 1.4-2.0 \quad(\mathrm{C}-$ $\left.\mathrm{CH}_{2}-\mathrm{C}\right), 2.1-2.4\left(\mathrm{C}-\mathrm{CH}_{2}-\mathrm{COO}\right), 3.28(\mathrm{~N}-$ $\left.\mathrm{CH}_{3}\right), 3.7-4.5\left(\mathrm{COO}-\mathrm{CH}_{2}-\mathrm{CH}_{2}-\mathrm{N}\right), \quad 7.57$ (6-H), and $11.2(\mathrm{~N}-\mathrm{H})$.

Anal. Calcd. for $\mathrm{C}_{20} \mathrm{H}_{26} \mathrm{O}_{8} \mathrm{~N}_{4}$ : C, 53, 33\%; H, $5.82 \%$; N, $12.44 \%$. Found: C, $52.66 \%$; H, $5.82 \% ; \mathrm{N}, 12.40 \%$.

Bis[2-(1-methyl-thymin-3-yl)ethyl]glutarate $\left(\mathrm{T}^{3}-\mathrm{T}^{3}\right)(3)$

This compound was prepared according to the same method described for compound 2 , except that it was obtained as an oil in $14 \%$ yield. IR ( $\mathrm{KBr}, \mathrm{cm}^{-1}$ ): 2950, 1730, 1700, 1640, 1450, 1340, 1310, 1260, 1190, 1170, 1060, 1020, 900 , and $760 .{ }^{1} \mathrm{H} \mathrm{NMR}\left(\mathrm{CDCl}_{3}, 25^{\circ} \mathrm{C}, 60 \mathrm{MHz}\right.$, ppm): $1.9\left({ }^{5} \mathrm{C}-\mathrm{CH}_{3}\right), 1.5-2.2\left(\mathrm{C}-\mathrm{CH}_{2}-\mathrm{C}\right)$, $2.1-2.6\left(\mathrm{C}-\mathrm{CH}_{2}-\mathrm{COO}\right), 3.3\left(\mathrm{~N}-\mathrm{CH}_{3}\right), 4.2$ $\left(\mathrm{COO}-\mathrm{CH}_{2}-\mathrm{CH}_{1}-\mathrm{N}\right)$, and $7.05(6-\mathrm{H})$.

$N, N^{\prime}-B i s[(2-($ thymin-1-yl)propionyl- $\alpha-$ alanyl]ethylenediamine $\left(\mathrm{T}^{1}-\alpha\right.$-Ala-ED- $\alpha$-Ala$\left.\mathrm{T}^{1}\right)$ (4)

Compound 4 was prepared according to the method reported in the article. ${ }^{11}$

1,3-Bis[2-(thymin-1-yl)propionyl]diaminopropane (5a)

To a solution of $9(1.58 \mathrm{~g}, 0.008 \mathrm{~mol})$ in $20 \mathrm{ml}$ of DMF, pentachlorophenyl trichloroacetate (PCPCA) $(7 \mathrm{~g}, 0.016 \mathrm{~mol})$ and triethylamine $(1.1 \mathrm{ml}, 0.008 \mathrm{~mol})$ were added. The reaction mixture was stirred for $2 \mathrm{~h}$ at room temperature, and the precipitant was filtered off and washed thoroughly with acetone to obtain the activated ester of thymine (10) in $96 \%$ yield (3.43 g). IR ( $\left.\mathrm{KBr}, \mathrm{cm}^{-1}\right)$ : 3150, 3040, 2950, $2850,1780,1680,1645,1450,1380,1360,1310$, $1260,1205,1140,1100,1035,1000,880,860$, and 770 .

To a solution of compound 10 ( $3.38 \mathrm{~g}$, $0.0076 \mathrm{~mol})$ in $50 \mathrm{ml} \mathrm{DMF}, 1,3$-diamino propane $(0.28 \mathrm{~g}, 0.0038 \mathrm{~mol})$ and imidazole $(0.52$ $\mathrm{g}, 0.0076 \mathrm{~mol})$ were added and the reaction mixture was stirred for 1 day at $60^{\circ} \mathrm{C}$.
Table I. Yields and melting points of the bis-thymine derivatives

\begin{tabular}{ccc}
\hline Compound & Yield $/ \%$ & $\mathrm{mp} /{ }^{\circ} \mathrm{C}$ \\
\hline $\mathbf{5 a}$ & 87 & $237-239$ \\
$\mathbf{5 c}$ & 61 & $223-225$ \\
$\mathbf{5 d}$ & 61 & $228-229$ \\
$\mathbf{5 e}$ & 61 & $188-190$ \\
\hline
\end{tabular}

After the reaction, the solvent was distilled off and the residue was thoroughly washed with acetone to obtain compound $5 \mathrm{a}$ in $90 \%$ yield $(1.54 \mathrm{~g})$; mp $289-290^{\circ} \mathrm{C}$. IR $\left(\mathrm{KBr}, \mathrm{cm}^{-1}\right)$ : $3350,3180,2070,2970,2825,1670,1645,1550$, $1460,1440,1350,1275,1240,1215,1130,1035$, $1000,940,850,800$, and 760 .

The other bis-thymine derivatives $\left(\begin{array}{ll}5 \mathbf{5} & \mathbf{e}\end{array}\right)$ shown in Figure 2, were prepared by the same method as described above. The yields and melting points of these compounds are listed in Table I. The structures of these compounds were also confirmed by elementary analysis and NMR spectroscopy.

\section{Photolysis}

Photolyses of these compounds were carried out in solution and the film state. The photoreactions in solution were carried out in a $10 \mathrm{~mm}$ quartz cell. The samples were dissolved in DMF or in dimethyl sulfoxide (DMSO), and their concentrations were adjusted at $1 \times 10^{-4} \mathrm{moll}^{-1}$ as thymine units. The photodimerization was followed by UV spectrophotometer at $270 \mathrm{~nm}$. The light source was a Philips SP lamp (500-W superhigh pressure mercury lamp) filtered through a Toshiba UV-29 and a Corning 9-30 glass filters. Light internsities were determined by potassium ferrioxalate actinometry. ${ }^{11}$ The quantum yield for oxalic acid decomposition was 1, 24 at $313 \mathrm{~nm}$. Purified nitrogen gas was passed through the solution to displace the air before the irradiation.

Photolyses of the films were carried out by using monochromic light from a spectroirradiator, as well as a superhigh pressure 
mercury lamp. Solutions of the bis-compounds in DMF or DMSO were cast on the quartz substrates, and the solvents were removed under vacuum for 1 day to obtain thin films of the dimeric compounds. The films were exposed to the irradiation of a $2 \mathrm{~kW}$ Xe-Arc lamp through a diffracting latticed window with a narrow wavelength bands of $280 \pm 1 \mathrm{~nm}$.

\section{Instrumentation}

A JASCO SS-25 monochromator of $280 \mathrm{~nm}$ wavelength was used as the light source to determine the quantum yields of the dimeric compounds in solution. Photolysis was carried out with a Nihon Bunko (CRM-FA) spectroirradiator. The ultraviolet spectra were measured with a Nihon Bunko (UVIDEC-660) spectrophotometer. The molecular weight distribution of the photoreacted compounds were measured by gel permeation chromatography (GPC) using Toyo Soda HLC CP8000 with a thermostated column TSK gel G2500HT (Toyo Soda) and a UV detector operating at $270 \mathrm{~nm}$ with DMF as the eluent.

\section{RESULTS AND DISCUSSION}

\section{Material Synthesis}

The bis-thymine derivatives used are shown in Figure 2. Compound $\mathrm{T}^{1}-\mathrm{T}^{3}(2)$ was obtained by reaction of 1-(2-hydroxyethyl)thymine and glutaric anhydride followed by reaction of 1-methyl-3-(2-hydroxyethyl)thymine through carboxamide synthesis agent DCC, according to Scheme 1. The other dimeric compounds were obtained by the same method using ordered thymine derivatives. Bis-thymine diamide (5a-e) compounds were prepared by reaction of 1-(2-carboxyethyl)thymine and various diamines through activated ester method as shown in Scheme 2.

\section{Photolysis}

Thymine bases are very resistant to UV irradiation in dilute aqueous solution without a triplet sensitizer, while the thymines form photodimers in aggregated form, ice, dry films, $\mathrm{KBr}$ pelets, and oligomers and polymers. It is known that the triplet state is the precursor of the photodimer formed at low concentration. For thymine at room temperature, the singlet lifetime is much shorter $\left(10^{-12} \mathrm{~s}\right)$ relative to

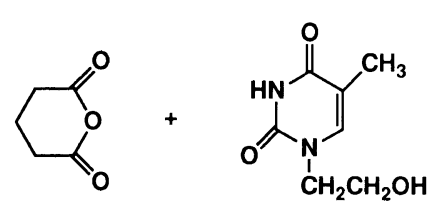

(6)

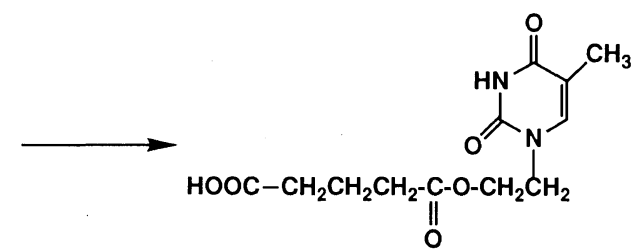

(7)
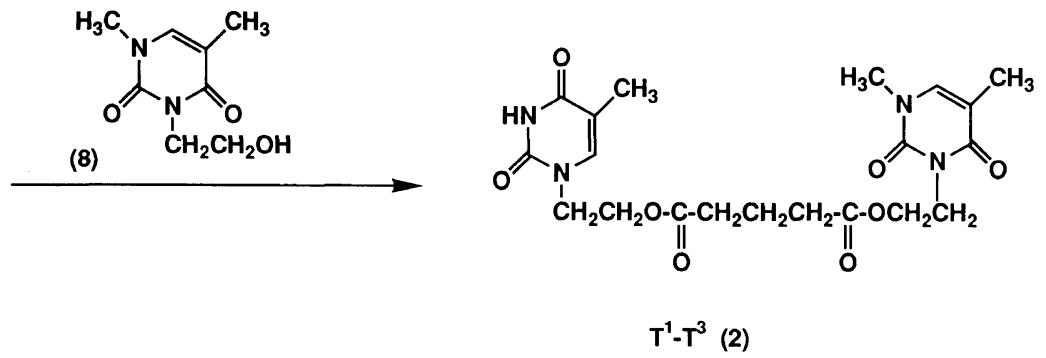

Scheme 1 
<smiles>Cc1cn(CCC(=O)O)c(=O)[nH]c1=O</smiles>

(9)

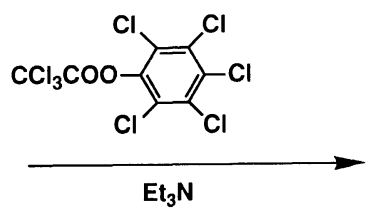

(10)

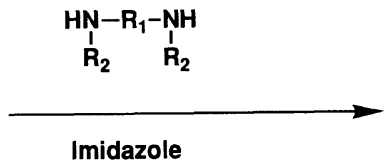

Imidazole<smiles>Cc1cn(CCCC(=O)N(P)PN(P)P)c(=O)[nH]c1=O</smiles>

(5)

Scheme 2

usual organic compounds $\left(>10^{-9} \mathrm{~s}\right)$. Thymine bases in dilute solution, therefore, cannot interact with another thymine in the groundstate in such a short single life time. The efficiency of intersystem crossing for thymine bases is low; furthermore, the bimolecular interaction between a triplet and ground-state molecules is highly inefficient, with selfquenching a more common result than production of a stable photodimer. ${ }^{1-6}$ When the long-lived triplet state is populated by sensitization, however, the bases can interact and dimerize efficiently.

In concentrated aqueous solutions, solid states, and polymers, thymine bases form aggregates or associated groups of stacked ground state molecules. Thymine bases in these states dimerize from a singlet precursor when bases are stacked and from a triplet precursor when they are not. It has been reported that the interaction of thymine bases is closely related to the photochemical reactivities. ${ }^{7-11}$

\section{Photochemical Reaction in Solution}

Photochemical reactions were studied in dilute solution of DMSO. The UV spectra data
Table II. UV Spectral data of the bis-thymine derivatives

\begin{tabular}{ccc}
\hline Compound & $\frac{\lambda_{\max }}{\mathrm{nm}}$ & $\frac{\varepsilon_{\max }}{1 \mathrm{~mol}^{-1} \mathrm{~cm}^{-1}}$ \\
\hline $\mathrm{T}^{1}-\mathrm{T}^{1}$ & 272 & 9000 \\
$\mathrm{~T}^{1}-\mathrm{T}^{3}$ & 272 & 9500 \\
$\mathrm{~T}^{3}-\mathrm{T}^{3}$ & 272 & 6300 \\
$\mathrm{~T}^{1}-\alpha-\mathrm{Ala}-\mathrm{ED}-\alpha-\mathrm{Ala}-\mathrm{T}^{1}$ & 272 & 8600 \\
\hline
\end{tabular}

of the bis-thymine derivatives, bonded by glutarate ester (1-3 in Figure 2) are given in Table II. The initial rates of the photochemical reactions irradiated by a $500 \mathrm{~W}$ superhigh pressure mercury lamp are shown in Figure 3, where $C_{0}$ and $C$ are the concentration of thymine units before and after irradiation of various doses, respectively. The photodimerizations of the bis-thymine compounds may be caused intramolecularly, because the thymine bases in dilute solutions hardly form photodimers intermolecularly. ${ }^{8}$

It was evident from the CPK model that the cyclobutane type photodimers produced intramolecularly in the photochemical reaction of these dimeric model have isomeric forms as 


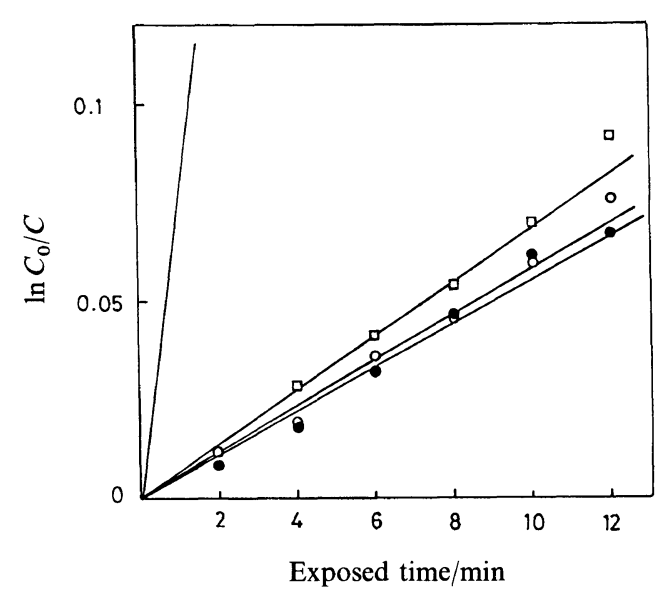

Figure 3. Initial Photodimerization of bis-thymine compounds in DMSO solution: $O, \mathrm{~T}^{1}-\mathrm{T}^{1} ; \square, \mathrm{T}^{1}-\mathrm{T}^{3} ; \mathrm{O}$, $\mathrm{T}^{3}-\mathrm{T}^{3} ;-$, poly $\left(\mathrm{MAOT}^{1}\right)$.

follows: cis-syn and trans-syn for $\mathrm{T}^{1}-\mathrm{T}^{1}$, cis-anti and trans-anti for $\mathrm{T}^{1}-\mathrm{T}^{3}$, cis-syn and cis-anti for $\mathrm{T}^{3}-\mathrm{T}^{3}$ (Figure 1 shows isomers of thymine photodimers). According to these isomerical structures, it was expected that the compounds forming syn isomers of the photodimers would have higher efficiency because of the lower sterical strain and higher termal stability of the syn type isomers. ${ }^{1}$ However, the initial reaction rates (Figure 3) of these bis-thymine derivatives $(\mathbf{1}-\mathbf{3})$ were approximately of the same order. This might be due to the fact that the flexible linking unit in these dimeric compounds caused fast conformational changes in solutions, and therefore the favored conformation of the thymine bases in $\mathrm{T}^{1}-\mathrm{T}^{1}(\mathbf{1})$ or $\mathrm{T}^{3}-\mathrm{T}^{3}(3) \mathrm{did}$ not affect the efficiency of the photodimerization in dilute solution. Furthermore, this flexibility caused the formation of unstable anti type isomers.

In Figure 3, for comparison, the photochemical reaction rate of the polymeric model, polymethacrylate with pendant thymine bases [poly(MAOT $\left.\left.{ }^{1}\right)\right]$, reported in our previous article, ${ }^{12}$ is also plotted. The photochemical reaction rates of the bis-thymine derivatives were about one tenth of that of the polymer
Table III. Quantum yields for intramolecular photodimerization in dilute solutions of the bis-thymine derivatives

\begin{tabular}{cc}
\hline Compounds & $\phi$ \\
\hline $\mathrm{T}^{1}-\mathrm{T}^{1}$ & 0.00072 \\
$\mathrm{~T}^{1}-\mathrm{T}^{3}$ & 0.00099 \\
$\mathrm{~T}^{3}-\mathrm{T}^{3}$ & 0.00076 \\
$\mathrm{~T}^{1}-\alpha$-Ala-ED- $\alpha$-Ala- $\mathrm{T}^{1}$ & 0.00033
\end{tabular}

model. This is related to the more rigid structures of the polymer chains, and therefore to the formation of stacked bases along the polymer chain, which is known to have very high photochemical efficiency. ${ }^{8-10}$

The quantum yields of the compounds $1-4$ in Figure 2 for intramolecular photodimerization in dilute solution are given in Table III. As evident from this table, the compounds bridged by the glutarate $(\mathbf{1}-\mathbf{3})$ ester have almost identical quantum yields. However, the quantum yield of compound 4 bridged by $\alpha$-alanyl ethylenediamine had a lower quantum yield. In this compound (4) dimerization takes place with a lower efficiency because of the long distance between the thymine bases and also the sterical hindrance of the methyl group in the linking compound. ${ }^{11}$ These findings are different from that of the polymeric model reported before. ${ }^{12}$ It was found there that the quantum yields of the poly(MAOT ${ }^{1}$ ) and poly $\left(\mathrm{MAOT}^{3} \mathrm{Me}^{1}\right)$ were higher than that of poly(MAOT ${ }^{1}$-alt-MAOT ${ }^{3} \mathrm{Me}^{1}$ ). This is due to the self association (stacking) of thymine bases in the two former polymers and poor stacking conformation of thymine bases in the latter polymer.

The photochemical reactions of the bisthymine compounds bonded by a diamide linkage (5) were studied in DMF and DMSO solution. These compounds showed no photochemical reaction without adding a triplet sensitizer (Figure 4). This shows that intramolecular photodimerizations do not occur in these compounds because of the long distance of the thymine bases and rigid 


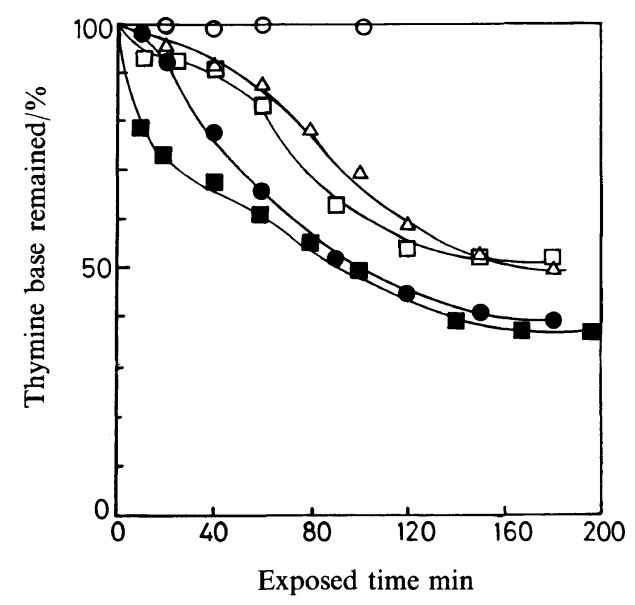

Figure 4. Photochemical reactions of the compound 5 in DMF solution; $\bigcirc$, without sensitizer $[\mathbf{O}, \mathbf{5 b} ; \square, \mathbf{5 c}$; $\square$ 5d; $\triangle$, 5e] with acetone sensitizer.

structure of the linking compound. That is, no stacked conformation between the thymine bases in the molecule would be formed and the photodimerization reaction could only occur intermolecularly by a triplet mechanism through a suitable sensitizer.

The results for compound 5 obtained by using acetone as a triplet sensitizer are shown in Figure 4. The mole fraction of acetone contained in the DMF solution of each compound was the same and adjusted at $4 \times 10^{-6} \mathrm{moll}^{-1}$ relative to the concentration of $1.2 \times 10^{-7} \mathrm{moll}^{-1}$ of the bis-thymine compound.

\section{Photolysis in the Film State}

The results of the photodimerization of the bis-thymine derivatives $\mathrm{T}^{1}-\mathrm{T}^{3}(2), \mathrm{T}^{3}-\mathrm{T}^{3}$ (3) and $\mathrm{T}^{1}-\alpha$-Ala-ED- $\alpha$-Ala- $\mathrm{T}^{1}$ (4) in the film state, exposed to the irradiation of a monochromic light at $280 \mathrm{~nm}$ are plotted in Figure 5. For the compound $\mathrm{T}^{1}-\mathrm{T}^{1}$, a clear transparent film could not be obtained. In this figure, the thymine bases remaining after exposure of varying doses are plotted versus the $\log E$; where $E$ represents the energy of exposed light. From this figure, the photodissociation rate of the compound $\mathrm{T}^{3}-\mathrm{T}^{3}$ is

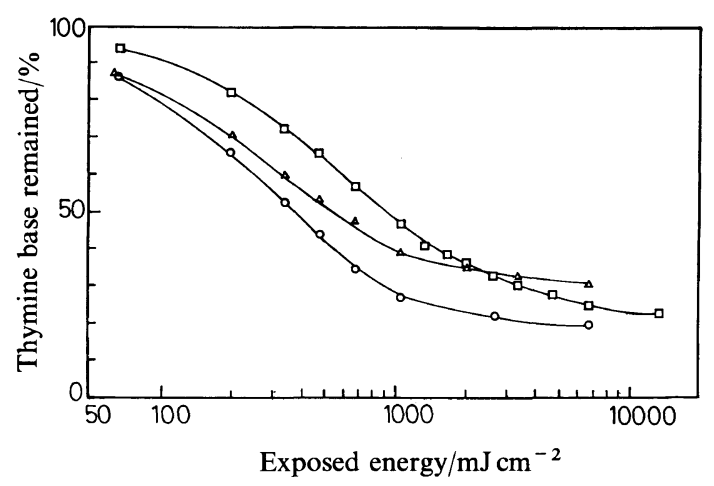

Figure 5. Photochemical reactions of the bis-thymine compounds in the film state: $\square, T^{1}-T^{3} ; O, T^{3}-T^{3} ; \triangle$, $\mathrm{T}^{1}-\alpha-\mathrm{Ala}-\mathrm{ED}-\alpha-\mathrm{Ala}-\mathrm{T}^{1}$.

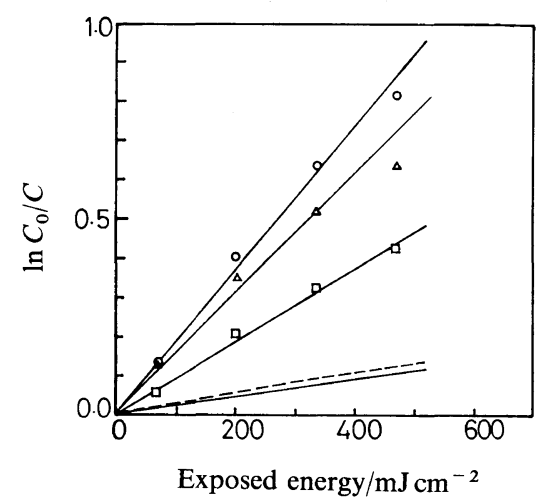

Figure 6. Initial photodimerization of the bis-thymine compounds in the film state: $\square, \mathrm{T}^{\mathbf{1}}-\mathrm{T}^{3} ; \mathrm{O}, \mathrm{T}^{3}-\mathrm{T}^{\mathbf{3}} ; \triangle$, $\mathrm{T}^{1}-\alpha$-Ala-ED- $\alpha$-Ala- $\mathrm{T}^{1} ;$ - , poly $\left(\mathrm{MAOT}^{1}\right),---$, poly$\left(\mathrm{MAOT}^{3} \mathrm{Me}^{1}\right)$.

seen to be comparatively higher than the other two dimeric model, and the photodimerization rates increase, in the order $T^{3}-T^{3}>T^{1}-\alpha-$ Ala-ED- $\alpha-A l a-T^{1}>T^{1}-T^{3}$. This might be related to the fact that the conformations of the thymine bases in these compounds are favorable for stacking, at the same increasing order due to the CPK model.

The initial photodimerization rates of these compounds were plotted versus the exposed energy as shown in Figure 6. The results of the polymeric models [poly $\left(\mathrm{MAOT}^{3} \mathrm{Me}^{1}\right)$ and poly $\left(\mathrm{MAOT}^{1}\right)$ ] were plotted in the same figure for comparison. ${ }^{12}$ The photodimerization rates of the bis-thymine compounds are about 


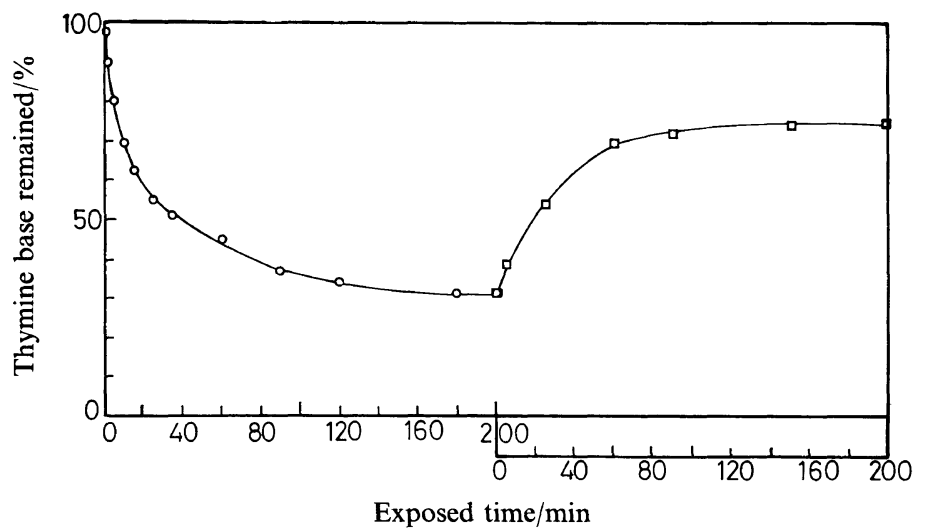

Figure 7. Photochemical reactions of the compound $5 \mathbf{a}$ in the film state. $\bigcirc$, photodimerization reaction upon UV light above $270 \mathrm{~nm}$; $\square$, photodissociation reaction with UV light at $254 \mathrm{~nm}$.

ten times larger than that of the polymeric model, which is opposed to the results of the photodimerization in the solution (Figure 3). This might be related to the fact that the photodimers of polymers in solution are formed intramolecularly through a singlet precursor as well as a triplet precursor, and the quantum yield through single state is higher than that through triplet state, whereas that of the dimeric models is formed only by a triplet precursor. $^{8-10}$ In the film state, however, the stacked bases would be formed intra- and intermolecularly in the dimeric models too, and photodimerization occurs through singlet as well as triplet states. In addition, in film state, the rate of the photodimerization of the thymine bases in the polymeric models would be reduced, because movement of the thymine bases is restricted in the polymer film with higher $T_{\mathrm{g}}$ value. ${ }^{10}$

The results of the photolyses of the bisthymine compounds bonded by the amide linkage are shown in Figures 7 and 8. Opaque films were obtained for compounds $\mathbf{5 a}, \mathbf{5 b}$, and 5e. For compound $\mathbf{5 a}$, transparent films were obtained from a $40 \%$ aqueous methylamine, as plotted in Figure 7, and for compounds $\mathbf{5 b}$ and 5e, transparent films were obtained from DMF and DMSO solutions plotted in Figure 8. For compound $\mathbf{5 a}$, the photodimerization

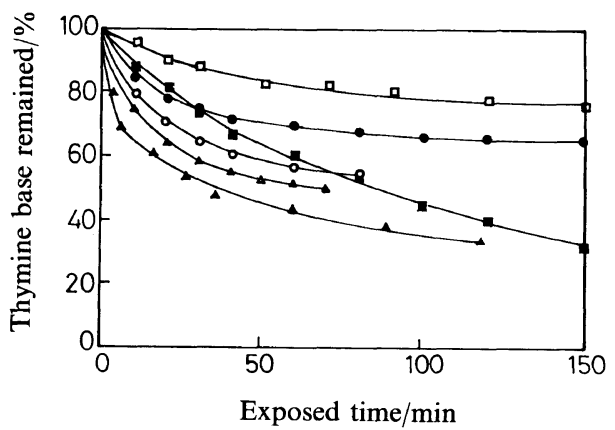

Figure 8. Photochemical reactions of the compounds $\mathbf{5 b}$ and $5 \mathbf{e}$ in the film state: $\bigcirc, \mathbf{5} \mathbf{b}$ films from DMF and DMSO solutions, respectively; $\square, \mathbf{\square}, \mathbf{5 e}$ films from DMF and DMSO solutions, respectively; $\boldsymbol{\Lambda}, \mathbf{5 a}$ film from methylamine solution; $\triangle$, $\mathbf{5 b}$ with adding acetophenone.

reaction was then confirmed by photodissociation of the photodimers by irradiation of UV light from a low pressure mercury lamp with main intensity at $254 \mathrm{~nm}$. The initial rate of photodimerization of compound $\mathbf{5 a}$ is higher than that of $\mathbf{5 b}$ and $\mathbf{5 e}$, which might be due to some intramolecular photodimerization in $\mathbf{5 a}$, because of more flexible and less distance of the thymine bases. The rate of photodimerization of $\mathbf{5 b}$ slightly increased by the addition of acetophenone as a triplet sensitizer.

In Figure 8, the effects of solvent used for preparation of films are shown. The rate of photodimerization of 5e film from DMSO was 

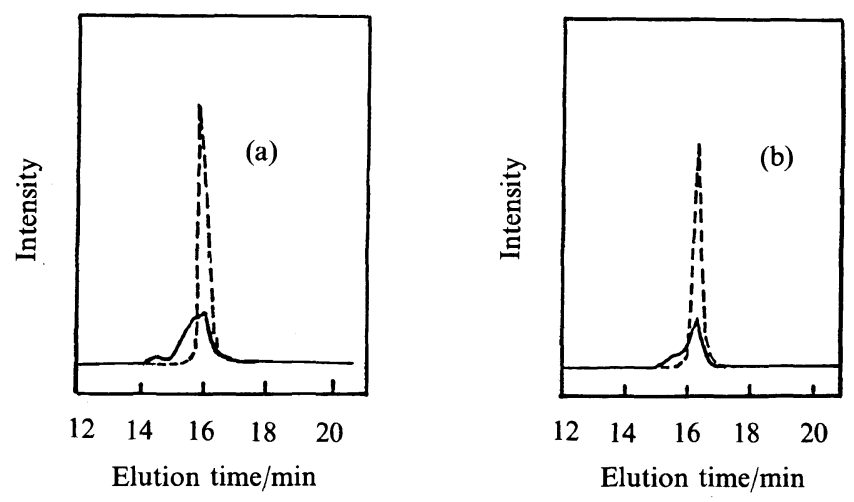

Figure 9. Gel permeation chromatograms of $\mathbf{5 b}$ (a) and $\mathbf{5 d}$ (b), in dilute solutions exposed to the irradiation of UV light above $270 \mathrm{~nm}$ : ---, before irradiation; - , after $40 \mathrm{~min}$ irradiation by superhigh pressure mercury lamp.
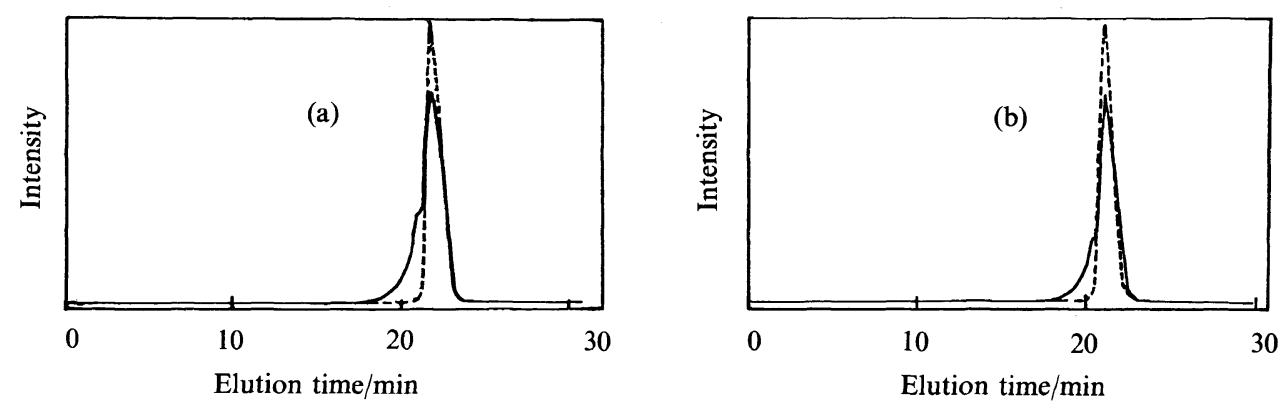

Figure 10. Gel permeation chromatograms of (a) $T^{1}-T^{3}$, (b) $T^{1}-\alpha$-Ala-ED- $\alpha-A l a-T^{1}$, in the film state before and after irradiation of UV light at $280 \mathrm{~nm}$ : ---, before irradiation; -, after irradiation of $6.83 \mathrm{~J} \mathrm{~cm}^{-2}$ dose.

higher than that from DMF. For compound $\mathbf{5 b}$, however, the a reverse solvent effect was observed. The effect of solvent used for preparation of the films might be related to the manner of stacking between the thymine bases in the molecule. In the film of $\mathbf{5 e}$ from the DMSO solution, the thymine bases may stack in a position which is a suitable precursor for the photodimer. Similar results were reported for the photodimerization of thymine crystals. The thymine crystal from water forms the photodimer, but the crystals from ethanol or from sublimation cannot form the photodimer. $^{1}$
GPC Study of the Bis-Thymine Derivatives During Photoreaction

Molecular weights of the photoreacted compounds were measured by the GPC method in solution as well as in the film state. Typical chromatograms for compounds $\mathbf{5 b}$ and $\mathbf{5 d}$ are shown in Figure 9. It is revealed from these chromatograms that oligomeric and polymeric compounds are produced by the photoreaction of these compounds even in very dilute solution in the presence of acetone as a sensitizer. This confirms the photodimerization of thymine in the bis-thymine derivatives with rigid structure of the linking compounds to occur intermolecularly to give a polymer containing thymine photodimer units.

The results of GPC measurements for 

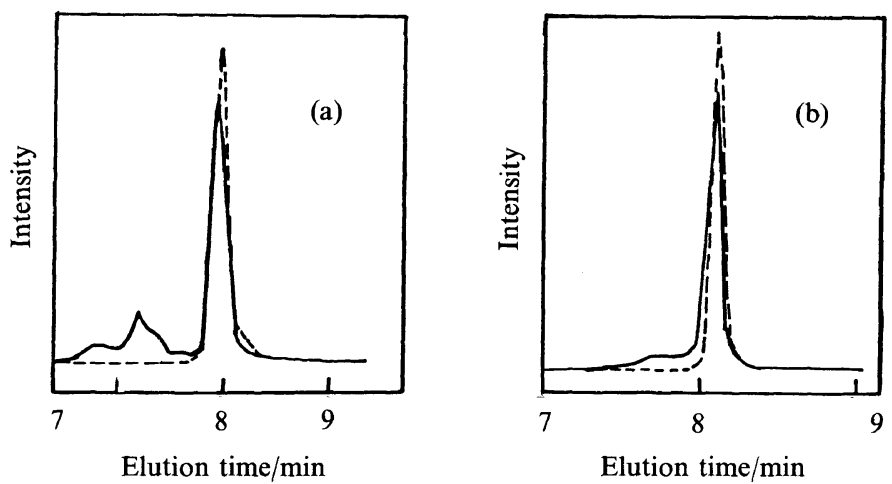

Figure 11. Gel permeation chromatograms of (a) $5 \mathbf{b}$ and (b) $5 \mathbf{e}$ in the film state before and after irradiation of UV light above $270 \mathrm{~nm}$ : ---, before irradiation; --, after $360 \mathrm{~min}$ irradiation by superhigh pressure mercury lamp.

compounds $\mathrm{T}^{1}-\mathrm{T}^{3}(2), \mathrm{T}^{1}-\alpha$-Ala-ED- $\alpha$-Ala$\mathrm{T}^{1}(\mathbf{4})$, as well as the compounds $5 \mathrm{~b}$ and $5 \mathbf{e}$ in the film state, before and after irradiation are shown in Figures 10 and 11, respectively. Oligomers and polymers are produced after photolyses of these compounds in the film state. This suggests that the photolyses of the bis-thymine derivatives in the film state caused intermolecular dimerization even for those with flexible linking compound. The molecular weights of the polymers from $\mathbf{5 b}$ and $5 \mathbf{e}$, however, were higher than those from 2 and 4 which may contain the intramolecular photodimer in addition to the intermolecular photodimer.

\section{CONCLUSIONS}

Various bis-thymine derivatives with various conformation and spacing were prepared and their photochemical reactions in solution and film state were studied. From the photochemical reaction, it was found that only the intramolecular photodimerization occurred in the bis-compounds with flexible linking substance in solution, whereas in the film state, intramolecular photodimerization occurred competitively with the intermolecular ones. However, the intramolecular photodimerization was suppressed in the bis-thymine compounds incorporating a rigid linking substance, and hence, photodimerization of these compounds led to the photopolymerization of them. The photopolymerization of these compounds may possibly make them applicable to negative-type photoresists. However, due to the limited solubility of the bis-thymine compounds with rigid linking substance and poor casability silicon wafes and forming films, photolithographic tests could not be carried out. We are investigating the structure of the dimeric model compound, which will be reported in the near future.

\section{REFERENCES}

1. G. J. Fisher and H. E. Johns, "Photochemistry and Photobiology of Nucleic Acids," S. Y. Wang, Ed., Vol. I, Academic, New York, 1976, p 225.

2. S. Y. Wang, Nature, 188, 844 (1960).

3. J. Eisinger and A. A. Lamola, Mol. Photochem., 1, 209 (1969).

4. D. Weinblum, Photochem. Photobiology, 12, 509 (1970).

5. T. M. Garestier, M. Charlier, and C. Helen, "Photochemistry and Photobiology of Nucleic Acids," S. Y. Wang, Ed., Vol. I, Academic, New York, 1976, p 381.

6. N. J. Leonard, K. Golankiewicz, R. S. Mccredie, S. M. Johnson, and A. C. Paul, "Photochemistry and Photobiology of Nucleic Acids," S. Y. Wang, Ed., Vol. I, Academic, New York, 1976, p 265.

7. Y. Kita, Y. Inaki, and K. Takemoto, J. Polym. Sci., 
Polym. Chem. Ed., 18, 427 (1980).

8. Y. Kita, T. Uno, Y. Inaki, and K. Takemoto, $J$. Polym. Sci., Polym. Chem. Ed., 19, 477 (1981).

9. Y. Kita, T. Uno, Y. Inaki, and K. Takemoto, $J$. Polym. Sci., Polym. Chem. Ed., 19, 2347 (1981).

10. Y. Kita, T. Uno, Y. Inaki, and K. Takemoto, $J$. Polym. Sci., Polym. Chem. Ed., 19, 1733 (1981).
11. Y. Suda, M. Kono, Y. Inaki, and K. Takemoto, $J$. Polym. Sci., Polym. Chem. Ed., 22, 2427 (1984).

12. M. J. Moghaddam, S. Hozumi, Y. Inaki, and K. Takemoto, Polym. J., 21, 203 (1989).

13. C. G. Overberger and Y. Inaki, J. Polym. Sci., Polym. Chem. Ed., 17, 1739 (1979). 